\title{
Performance enhancement of shunt active power filter using soft computing techniques
}

\author{
Annu Govind ${ }^{1}$, Vijay Kumar Tayal' ${ }^{2}$, Prakash Kumar ${ }^{3}$ \\ ${ }^{1,2}$ Department of Electrical and Electronics Engineering, Amity University, Uttar Pradesh, Noida, India \\ ${ }^{3}$ Department of Electrical Engineering, Amity University, Patna, India
}

\section{Article Info \\ Article history: \\ Received Feb 22, 2021 \\ Revised Mar 16, 2021 \\ Accepted Apr 4, 2021}

\section{Keywords:}

Artificial neural network Gravitational search algorithm Power quality Proportional integral controller Shunt active power filter

\begin{abstract}
Nowadays, active power filter (APF) is the most popular device for harmonic compensation. This paper presents the soft computing techniques for compensation of currents harmonics using a shunt active power filter (SAPF). The method includes a 3-phase supply system with a currentcontrolled voltage source converter (CC-VSC) having an input coupling inductor and output tank capacitor for a self-supported DC bus. The performance of the active power filter can be enhanced by using soft computing techniques such as artificial neural network (ANN) controller and gravitational search algorithm (GSA) for generating control signals of the SAPF. The current reference is calculated to compensate source current THD with synchronous reference frame (SRF) technique with proportional integrator (PI) controller. From the result, it is evident that both the soft computing techniques reduce the computational time \& fast convergence which improves the filter performance during the transient period and makes it self-tuned. The proposed structure is simulated using MATLAB/Simulink and subsequently experimentally verified. The presentation of the system is originated to be suitable for numerous features of power quality enhancement structure.
\end{abstract}

This is an open access article under the CC BY-SA license.

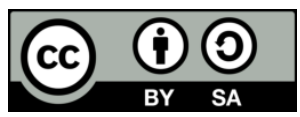

\section{Corresponding Author:}

Annu Govind

Department of Electrical and Electronics Engineering

Amity University

Uttar Pradesh, Noida, India

Email: annugovind@gmail.com

\section{INTRODUCTION}

With the use of power electronic-based devices, various power related issues such as load unbalance and harmonics are injected in modern distribution systems [1], [2]. These loads are termed non-linear loads. There are two types of non-linear load, current \& voltage fed loads. To understand with the example that phase-controlled converter with an inductor as the load is nonlinear in nature and the converter with resistive load are voltage source type loads [3]. Due to the unbalanced operation and non-linearity, these devices draw an instantaneous reactive power and inject harmonics current. The unbalanced operation increases neutral current [4]. The unbalanced voltages, need of reactive power, voltage sag and swell, current and voltage harmonics are the power quality issues that are common due to power electronics-based nonlinear loads.

It is essential to change and applied resolution to expand the quality of power in the system. Traditionally to overcome such PQ issues passive power filters are used but due to their drawbacks like fixed compensation, retuning, series/ parallel resonance \& filtering characteristics strongly affected by source impedance, etc. To overcome such problems, APFs are presented in electrical systems. Several compensation 
techniques have been stated to regulate APF's with the advancement in power electronics[5], [6]. To achieve the goal of power quality using APF, the main task is the exact estimation of compensating current \& generation of the reference current [7], [8]. PDF controlling based on soft computing techniques are also known as artificial intelligence (AI) is well known due to its capability to handle complex \& non-linear systems without much information about exact mathematical models [9]-[11]. The ANN is the most popular out of these techniques as it is having many advantages like after training it works with incomplete knowledge, even provide an output if one or more cells of ANN may be corrupted, It is having a distributed memory [12]

SAPF generates compensating current of similar degree but of reverse sign to that the harmonic current is produced by loads which is nonlinear in nature. In this article, the performance of SAPF has been improved using AI techniques. The DC-link voltage of VSI topology of APF regulated by GSA tuned PI controller and ANN controller which are applied for optimal PWM generation to reduce losses and make the system more robust. PLL synchronization is used for reference current generation. Hysteresis current controller is applied for producing switching signals for switches. It is generated by a comparison of reference signals and sources current. PI controller is most widely adopted in commercial applications as they are having simple structure, ease to design, and low cost [13]-[16]. Under sag conditions, conventional approaches use constant gain PI controllers to raise the fault between the reference voltage and the DC connection voltage [17]-[21]. As a result, compensation for PQ distortion at the point of typical coupling is robbed (PCC) [22].

\section{GSA BASED SAPF OPTIMIZATION}

Figure 1 presents the proposed model of SAPF using GSA tuned PI controller. Figure 2 presents the proposed Flowchart for proposed GSA optimization. Gravitational search algorithm (GSA) [23], [24] is a process constructed on Newton's law of gravity. It revealed that every particle interest's other particle using gravitational force [25] The gravitational force (F) is clear by (1),

$$
F=\mathrm{G} \frac{\mathrm{M}_{1} \mathrm{M}_{2}}{\mathrm{R}^{2}}
$$

where,

$M_{1}$ and $M_{2}=$ Mass of the particles,

$\mathrm{G}=$ Gravitational constant,

$\mathrm{R}=$ Particles distance

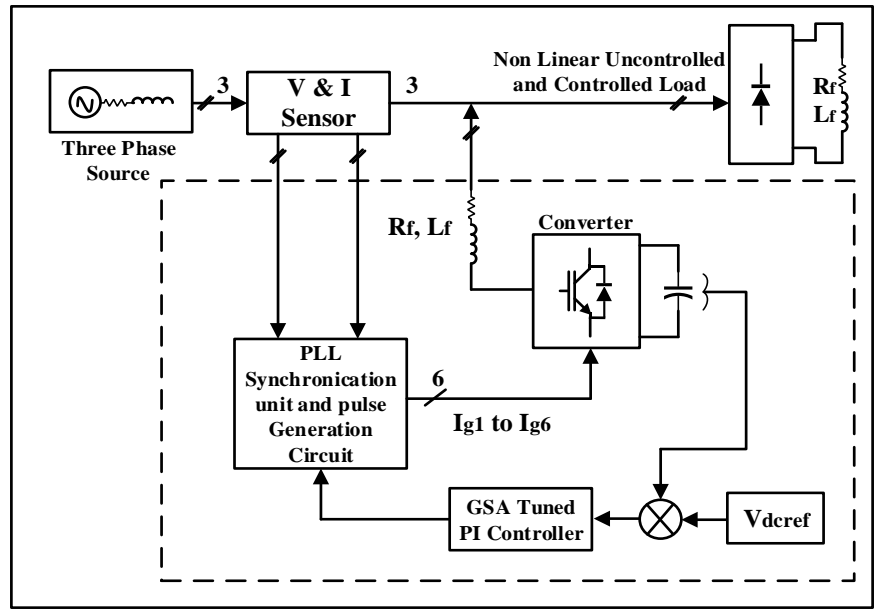

Figure 1. Block diagram of proposed SAPF based on GSA tuned PI controller

As per Newton's second law which states that acceleration of particle is ratio of force applied on a particle to its mass as state in (2).

$$
a=\frac{\mathrm{F}}{\mathrm{M}}
$$


To describe GSA, each mass (agent) is represented by its inertial mass, position, submissive gravitational mass, and dynamic gravitational mass. Inertial mass is an impact rate of a body changing its motion when force is providing. Dynamic gravitational mass is the amount of gravitational field forte for a specific object and submissive gravitational mass is the interaction of a body with gravitational field strength measurement.

Let the structure of ' $n$ ' agents (masses) the $\mathrm{i}^{\text {th }}$ location of an agent $\mathrm{S}_{\mathrm{i}}$ is given by (3).

$$
\mathrm{S}_{\mathrm{i}=}\left(\mathrm{S}_{\mathrm{i}}{ }^{1} \ldots, \mathrm{S}_{\mathrm{i}}{ }^{\mathrm{d}} \ldots, \mathrm{S}_{\mathrm{i}}{ }^{\mathrm{n}}\right)
$$

where $\mathrm{i}$ is $1,2, \ldots \mathrm{n}$

$\mathrm{S}_{\mathrm{i}}{ }^{\mathrm{d}}$ shows the location of $\mathrm{i}^{\text {th }}$ mediator (mass) in $\mathrm{d}^{\text {th }}$ length. The force exerted on mass $\mathrm{i}$ from mass $\mathrm{j}$ at a precise time is characterized by (4).

$$
\begin{aligned}
& F_{i j}^{d}(\mathrm{k})=\mathrm{G}(\mathrm{k}) \frac{\mathrm{M}_{\mathrm{aj}}(\mathrm{k}) \times \mathrm{M}_{\mathrm{pi}}(\mathrm{k})}{\mathrm{R}_{\mathrm{ij}}(\mathrm{k})+\mathcal{E}}\left(\mathrm{x}_{\mathrm{j}}^{\mathrm{d}}(\mathrm{k})-\mathrm{x}_{\mathrm{i}}^{\mathrm{d}}(\mathrm{k})\right) \\
& \mathrm{R}_{\mathrm{ij}}(\mathrm{k})=\left\|S_{i}(k), S_{j}(k)\right\|_{2}
\end{aligned}
$$

$F_{i j}^{d}(\mathrm{k})$ is a force working on ' $\mathrm{i}$ ' from mass ' $\mathrm{j}$ ' at a specific time $\mathrm{k}, \mathrm{G}(\mathrm{k})$ is the gravitational constant \& it depends on time, $\mathrm{M}_{\mathrm{aj}}(\mathrm{k})$ is the dynamic gravitational mass of agent $\mathrm{j}, \mathrm{M}_{\mathrm{pi}}(\mathrm{k})$ is a submissive gravitational mass of agent $\mathrm{i}, \mathcal{E}$ is a minor constant and $\mathrm{R}_{\mathrm{ij}}(\mathrm{k})$ is the Euclidean distance among two mediators $\mathrm{i}$ and $\mathrm{j}$ as distinct by (5).

In $\mathrm{GSA}, \mathrm{G}(\mathrm{k})$ is given by $(6)$, where $\mathrm{G}_{0}$ is the primary value for $\mathrm{G}, \mathrm{T}$ is the total count of iterations and $\alpha$ is a parameter.

$$
\mathrm{G}(\mathrm{t})=\mathrm{G} 0 \exp \left(-\alpha \frac{k}{T}\right)
$$

The complete force $F_{i}^{d}(k)$ which acts on parameter $\mathrm{i}$ in $\mathrm{d}^{\text {th }}$ dimension is at random weighted addition of d-th components of the forces exerted from other agents (7). In this equation, randj is an arbitrary number lies between $[0,1]$.

$$
\mathrm{F}_{\mathrm{i}}^{\mathrm{d}}(\mathrm{k})=\sum_{\mathrm{j}=1, \mathrm{j} \neq \mathrm{i}}^{\mathrm{N}} \operatorname{rand}_{\mathrm{j}} \mathrm{F}_{\mathrm{ij}}^{\mathrm{d}}(\mathrm{k})
$$

By the Newton's second law, $a_{i}^{d}(k)$ is the acceleration of the agent $\mathrm{i}$ at time $\mathrm{t}$ in $\mathrm{d}^{\text {th }}$ direction $\&$ given by (8), where $M_{i i}$ is the inertial mass of $\mathrm{i}^{\text {th }}$ agent.

$$
a_{i}^{d}(k)=\frac{F_{i}^{d}(k)}{M_{i i}(k)}
$$

$V_{i}^{d}(k+1)$ is the velocity $\& S_{i}^{d}(k+1)$ is the position of an agent at time $(\mathrm{k}+1)$ characterized by (9) and (10) respectively.

$$
\begin{aligned}
& V_{i}^{d}(k+1)=a_{i}^{d}(k)+V_{i}^{d}(k) \times \text { rand }_{i} \\
& S_{i}^{d}(k+1)=V_{i}^{d}(k+1)+S_{i}^{d}(k)
\end{aligned}
$$

The active, passive \& inertial masses are given by using (11)-(13), where fit $t_{\mathrm{i}}(\mathrm{k})$ gives the fitness value of an agent at time $\mathrm{k}$.

$$
\begin{aligned}
& \left(M_{a i}=M_{p i}=M_{i i}=M_{i}, \mathrm{i}=1,2, \ldots . . \mathrm{n}\right) \\
& \mathrm{m}_{1}(\mathrm{k})=\frac{\mathrm{fit}_{\mathrm{i}}(\mathrm{k})-\operatorname{worst}(\mathrm{k})}{\operatorname{best}(\mathrm{k})-\operatorname{worst}(\mathrm{k})}
\end{aligned}
$$

Where, $M_{i}(k)=\frac{m_{i}(k)}{\sum_{j=1}^{n} m_{i}(k)}$

For minimization/maximization, worst $(\mathrm{k})$ \& best (k) are characterized by (13) and (14). 


$$
\begin{aligned}
& \operatorname{best}(k)=\min _{j \in\{1, \ldots n\}}\left(\max _{j \in\{1, \ldots n\}}\right) f i t_{j}(k) \\
& \text { worst }(k)=\max _{j \in\{1, \ldots n\}}\left(\min _{j \in\{1, \ldots n\}}\right) f i t_{j}(k)
\end{aligned}
$$

For obtaining good coordination between examination and exploitation, the numbers of agents are to be reduced with time elapse and the best agents will interact with the other agents. Therefore (7) can be rewritten as (15).

$$
F_{i}^{d}(k)=\sum_{j \in N_{\text {best }}, j \neq i}^{n}\left(\operatorname{rand}_{j} F_{i j}^{d}(k)\right)
$$

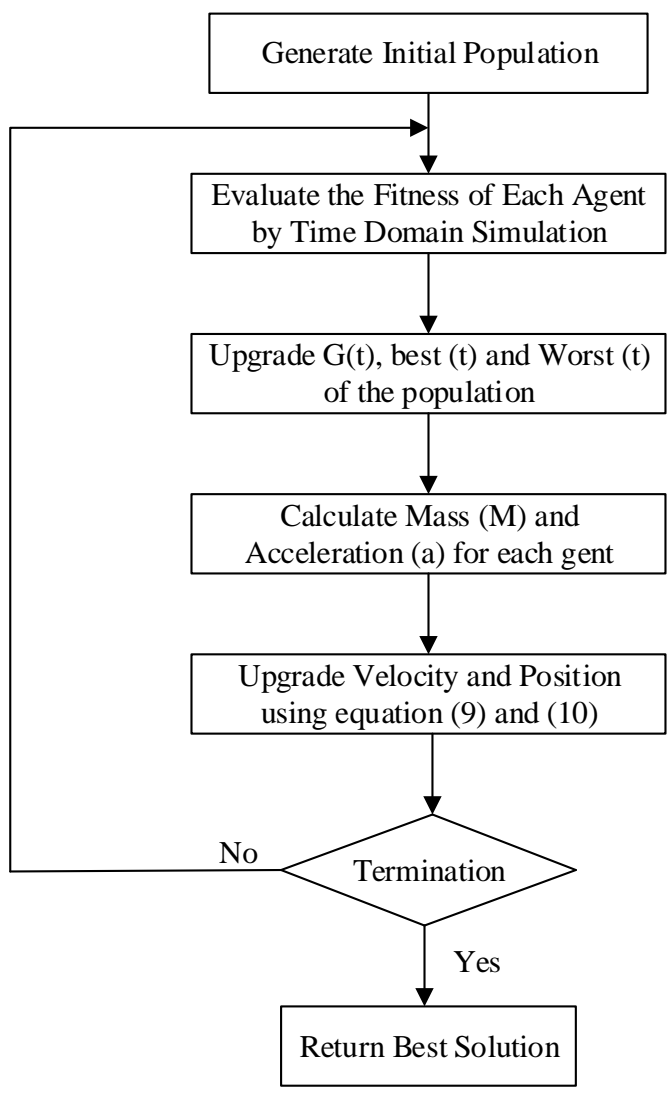

Figure 2. Flowchart for proposed GSA optimization

\section{ANN BASED SAPF OPTIMIZATION}

Artificial neural network (ANN) is an iterative approach based on human brain neuron training [26]-[29]. The basic structure of the developed ANN has been shown in Figure 3(a). Neurons in multi-layer artificial neural networks are structured closely to those in the human brain. Each neuron has a set of coefficients that bind it to other neurons. Knowledge is transmitted to these access points during preparation so that the network can be understood. Levenberg-Marquardt backpropagation training algorithm is used to renew the weight $\&$ bias values. Output $\&$ input layer consist of 1 neuron $\&$ hidden layers are 20 neurons. For a given search problem the input \& output layers remains constant, and the number of hidden layers dictates the precision of ANN. The proposed model of 3 phase, VSI with the R-L element as the nonlinear load is shown in Figure 3(b). Phase lock loop is used for reference current generation. The error between link voltage (DC) \& reference voltage $\left(\mathrm{V}_{\text {ref }}\right)$ is fed to ANN controller. As the DC link supplies switching losses of VSI, hence its voltage regulation is done by ANN Controller. THE proposed ANN controller is a multilayer neural network. It is trained to get reference current to generate reference 3 -phase source current $\&$ generate gating pulse using 6 IGBT switches for SAPF. It consists of APL loss component to keep the average DC link voltage unchanged. In this ANN controller based on a multilayer, the feed-forward type is used. 


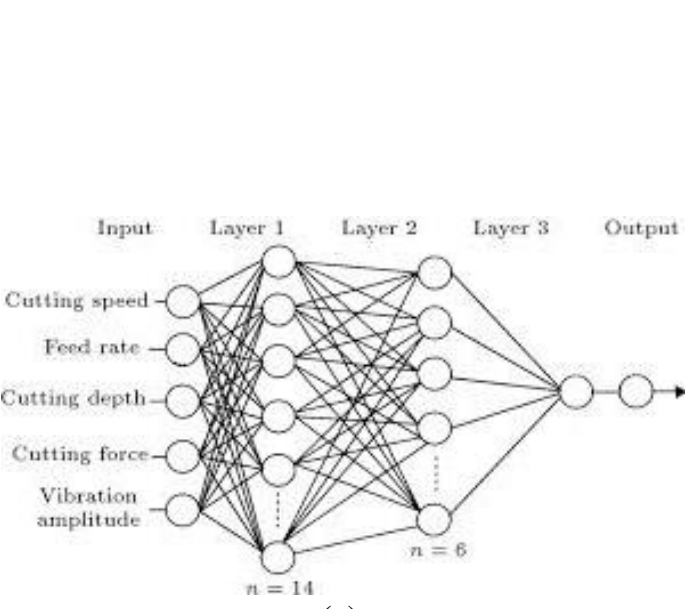

(a)

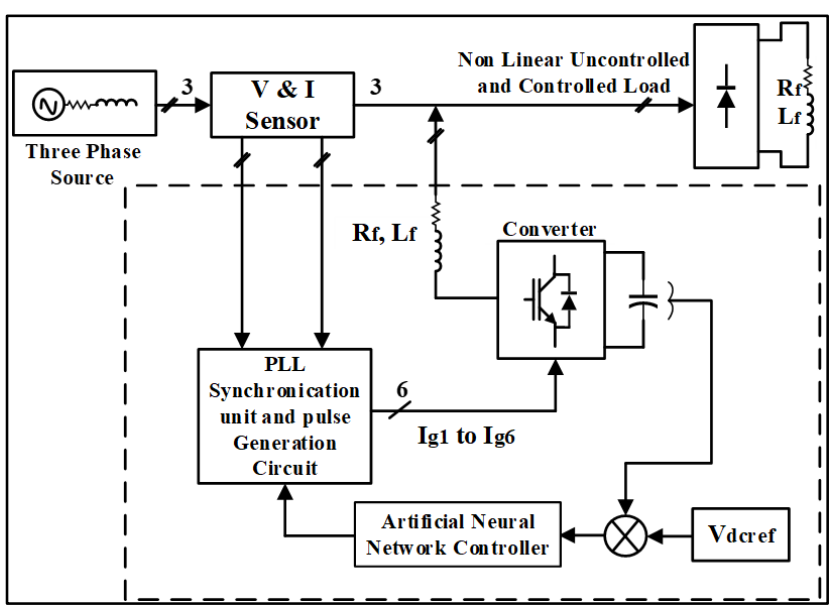

(b)

Figure 3. These figures are: (a) Developed ANN, (b) Proposed ANN based SAPF

\section{RESULTS}

MATLAB/Simulink prototypical of SAPF with projected controllers is established and tested. Three-phase shunt active power filter arrangement has been represented in Figure 1 and Figure 3. The proposed model consists of a 3-phase ac source, SAPF, R-L type nonlinear load \& proposed controllers. A PI controller is used to maintain the DC bus voltage of the VSC to $200 \mathrm{~V}$. Figure 4 and Figure 5 are the present performance of the system. Simulation time is applied as $0.0 \mathrm{sec}$ to $0.40 \mathrm{sec}$.
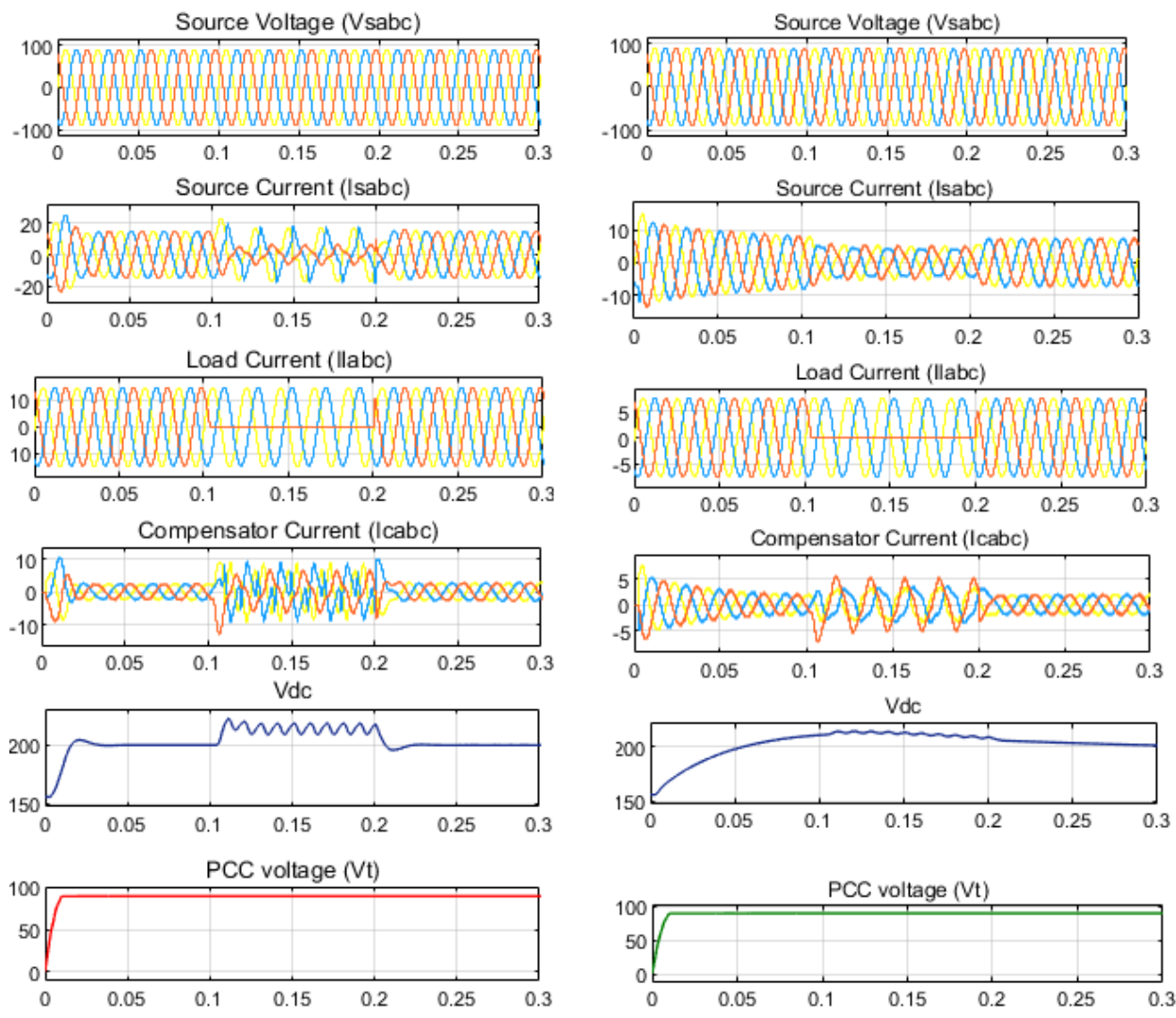

(a)

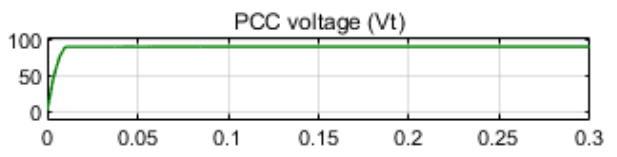

(b)

Figure 4. SAPF performance with: (a) GSA tuned PI, (b) ANN 

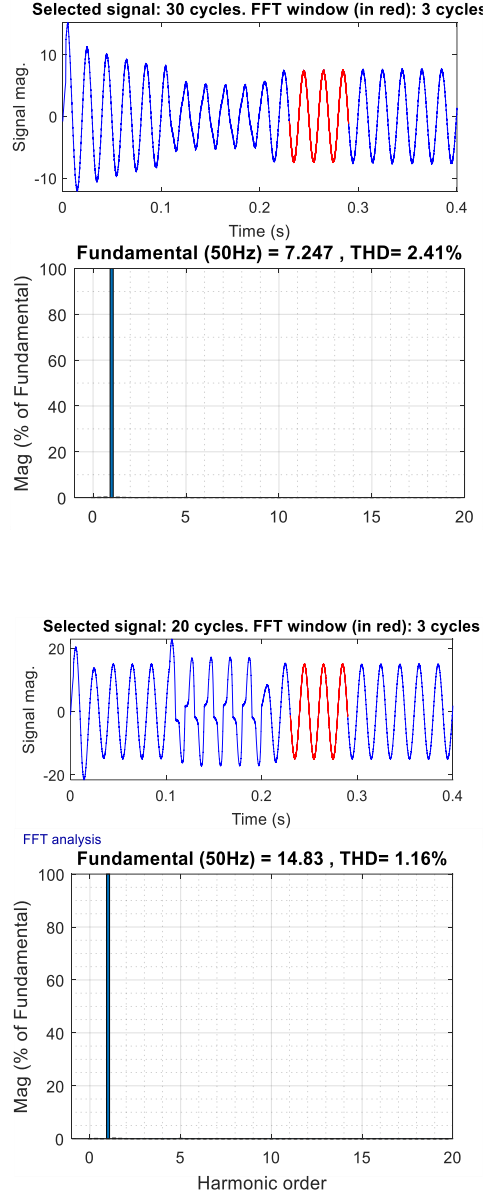

Figure 5. Harmonic spectra of source current: (a) Compensation with GSA tuned PI, (b) Compensation with ANN

Simulation is performed by proposed GSA \& ANN algorithm \& obtained results are compared APF is switch on 0.1 seconds. Figure 4 depicts the system's complex output for the nonlinear load. It presents the waveform of PCC voltage $\left(\mathrm{V}_{\mathrm{t}}\right)$, Source voltage $\left(\mathrm{V}_{\text {sabc }}\right)$, load current $\left(\mathrm{I}_{\text {Labc }}\right)$, input supply current (Is), compensator current $\left(\mathrm{I}_{\mathrm{Ca}}, \mathrm{I}_{\mathrm{Cb}}, \mathrm{I}_{\mathrm{Cc}}\right)$, and DC link voltage $\left(\mathrm{V}_{\mathrm{dc}}\right)$. It can be detected that under the dynamic \& steady-state process of the system, the supply current is balance and sin wave. The supply current is in phase with PCC voltage with unity power factor.

Figure 5 shows the harmonic spectrum of supply current $\left(\mathrm{I}_{\mathrm{sa}}, \mathrm{I}_{\mathrm{sb}}, \mathrm{I}_{\mathrm{sc}}\right)$. It is evident that harmonic distortion of supply current $\left(\mathrm{I}_{\mathrm{sa}}, \mathrm{I}_{\mathrm{sb}}, \mathrm{I}_{\mathrm{sc}}\right)$ are $02.41 \%, 02.43 \%$, and $02.43 \%$ correspondingly with GSA tuned PI and $1.14 \%, 1.16 \%$, and $1.16 \%$ for ANN tuned. The source current is specified by the IEEE-519 standard. Without compensation total harmonic distortion (THD) is $28.05 \%$ which is reduced to $2.41 \%$ by GSA tuned PI controller \& $1.14 \%$ from ANN controller.

The presented structure is subsequently experimentally verified. Figure 6 shows the source voltage waveforms, load, and compensating currents. It has been demonstrated that the presented technique works well even under unbalanced load conditions.

Both soft computing techniques are applied to provide optimal PWM generation. The primary advantage of PWM is that it minimizes the losses occurred due to switching. When the switch is closed (off) there is no current and when it is open (on) the current flows towards load, therefore there is no voltage drop across the switch. Hence power loss in both conditions (on/off) is almost zero [28]. Figure The harmonic analysis of supply and load current is depicted in Figure 7. THD values in the source present are 2.04 percent and 1.20 percent, respectively. The load current has a THD of $26.8 \%$. For harmonic reduction and load unbalancing, the VSC has been properly regulated. 


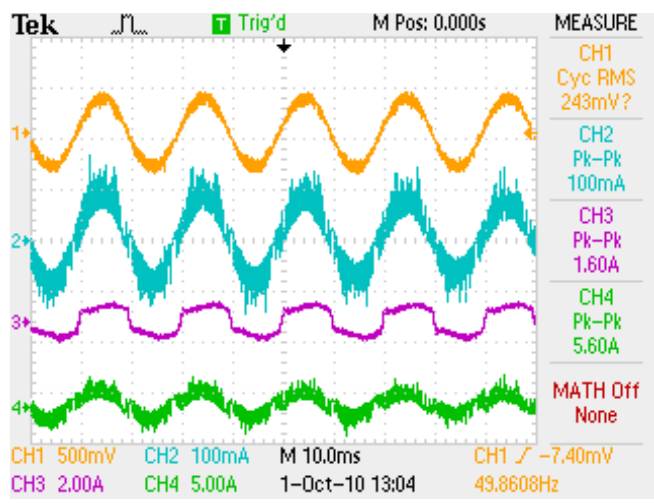

Figure 6. Supply voltages waveforms in steady-state condition

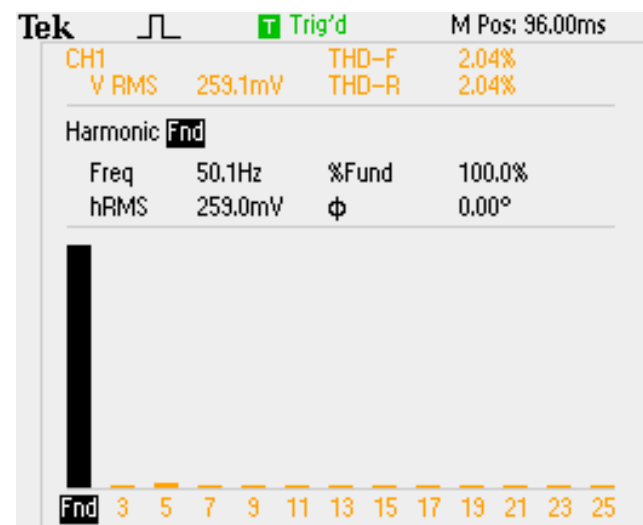

(a)

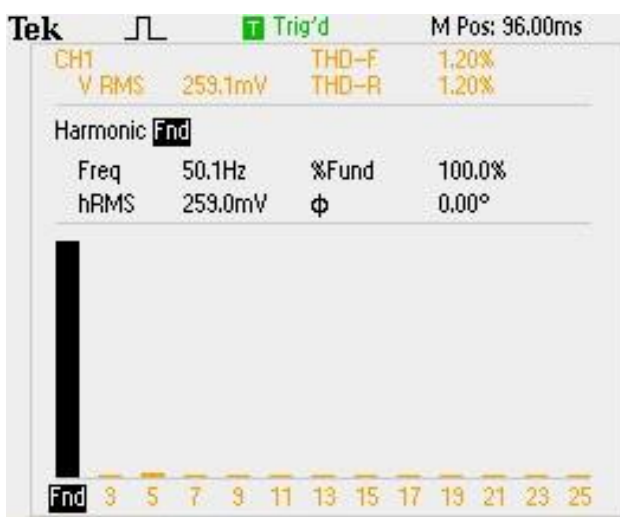

(b)

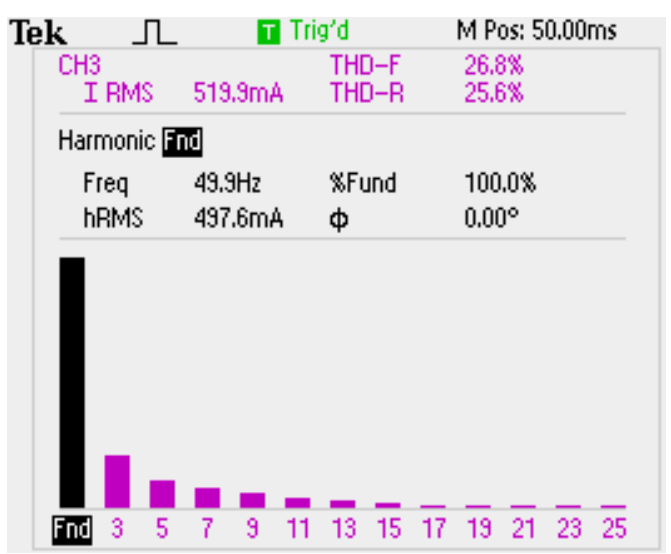

(c)

Figure 7. THD of source current: (a) Compensation with GSA tuned PI, (b) Compensation with ANN, (c) THD of load current

\section{CONCLUSION}

In this paper, SAPF performance has been analyzed by using soft computing techniques such as GSA tuned PI \& ANN-based controllers. The proposed models are implemented on MATLAB/Simulink \& their performance results are compared. The results obtained from GSA tuned PI controller show good compensation as well as less deviation in DC link voltage with faster settling time. ANN controller improves SAPF performance during the transient state as it having self-learning ability with parallel computation. Hence less computational time \& fast convergence obtained from both but in GSA the convergence rate becomes slow down in the next iteration and it may fall into the local optimal solution. The \% THD obtained from both are within IEEE standards. 


\section{ACKNOWLEDGMENT}

I'd like to express my heartfelt appreciation to Professor D. K. Palwalia for his insightful and enthusiastic support of this research work. I'd also like to thank my research supervisors, Dr. V. K. Tayal and Dr. Prakash Kumar, for their patient feedback and helpful critiques on this work. My thanks are also extended to Mr. Kuldeep Jayaswal and Dr. R. K. Kumawat for their valuable and constructive suggestions during the planning and development of this article. At Last, I'd like to express my deep gratitude to my husband and children for their unwavering love and motivation during my work.

\section{REFERENCES}

[1] R. K. Kumawat and D. K. Palwalia, "A comprehensive analysis of reduced switch count multilevel inverter," Australian Journal of Electrical and Electronics Engineering, vol. 17, no. 1, pp. 13-27, 2020, doi: 10.1080/1448837X.2019.1693884.

[2] B. S. Goud, B. L. Rao, and C. R. Reddy, "An intelligent technique for optimal power quality reinforcement in a grid-connected HRES system: EVORFA technique," International Journal of Numerical Modelling: Electronic Networks, Devices and Fields, vol. 34, no. 2, pp. 1-30, 2021, doi: 10.1002/jnm.2833.

[3] S. Ojha, and A. K. Pandey, "Close loop V/F control of voltage source inverter using sinusoidal PWM, third harmonic injection PWM and space vector PWM method for induction motor," International Journal of Power Electronics and Drive Systems, vol. 7, no. 1, pp. 217-224, 2016, doi: 10.11591/ijpeds.v7.i1.pp217-224

[4] A. V. Sant and M. H. Gohil, "ANN Based fundamental current extraction scheme for single phase shunt active filtering," 2019 IEEE international conference on electrical, computer and communication technologies (ICECCT), 2019, pp. 1-6, doi: 10.1109/ICECCT.2019.8869032.

[5] R. Dehini, A. Bassou, and B. Ferdi, "The harmonics detection method based on neural network applied to harmonics compensation," International Journal of Engineering, Science and Technology, vol. 2, no. 5, pp. 258267, 2010, doi: 10.4314/ijest.v2i5.60160.

[6] A. Govind and O. Govind, "Power quality improvement using active filters: A review," International Conference on Recent Trends in Engineering Science and Management (ICRTESM -2015), 2015, pp. 4289-4297.

[7] R. Anitha and S. Jeyadevi, "Gravitational search algorithm-based UPQC for power quality improvement of WECS," International Journal of Operational Research, vol. 37, no. 2, pp. 259-292, 2020, doi: 10.1504/IJOR.2020.105365.

[8] A. Bhattacharya and C. Chakraborty, "Predictive and adaptive ANN (Adaline) based harmonic compensation for shunt active power filter," 2008 IEEE Region 10 and the Third international Conference on Industrial and Information Systems, 2008, pp. 1-6, doi: 10.1109/ICIINFS.2008.4798496.

[9] C. M. Rahman and T. A. Rashid, "A new evolutionary algorithm: Learner performance based behavior algorithm," Egyptian Informatics Journal, vol. 22, no. 2, 2021, doi: 10.1016/j.eij.2020.08.003.

[10] M. Sujith and S. Padma, "Implementation of psoann optimized PI control algorithm for shunt active filter," Computer Modeling in Engineering \& Sciences, vol. 122, no. 3, pp. 863-888, 2020, doi: 10.32604/cmes.2020.08908.

[11] A. S. Shamsaldin, T. A. Rashid, R. A. Al-Rashid Agha, N. K. Al-Salihi, and M. Mohammadi, "Donkey and smuggler optimization algorithm: A collaborative working approach to path finding," Journal of Computational Design and Engineering, vol. 6, no. 4, pp. 562-583, 2019, doi: 10.1016/j.jcde.2019.04.004.

[12] J. M. Abdullah and T. Ahmed, "Fitness dependent optimizer: Inspired by the bee swarming reproductive process," in IEEE Access, vol. 7, pp. 43473-43486, 2019, doi: 10.1109/ACCESS.2019.2907012.

[13] R. E. Precup, R. C. David, E. M. Petriu, M. B. Radac, and S. Preitl, "Adaptive GSA-based optimal tuning of PI controlled servo systems with reduced process parametric sensitivity, robust stability and controller robustness," IEEE transactions on cybernetics, vol. 44, no. 11, pp. 1997-2009, 2014, doi: 10.1109/TCYB.2014.2307257.

[14] A. A. Imam, R. S. Kumar, and Y. A. Al-Turki, "Modeling and simulation of a pi controlled shunt active power filter for power quality enhancement based on p-q theory," Electronics, vol. 9, no. 4, Apr. 2020, doi: 10.3390/electronics9040637.

[15] S. Chourasiya and S. Agarwal, "A review: Control techniques for shunt active power filter for power quality improvement from non-linear loads," International Electrical Engineering Journal, vol. 6, no. 10, pp. 2028-2032, 2015.

[16] K. Jayaswal, D. K. Palwalia, and S. Kumar, "Analysis of robust control method for the flexible manipulator in reliable operation of medical robots during COVID-19 pandemic," Microsystem Technologies, vol. 27, pp. 21032116, 2021, doi: 10.1007/s00542-020-05028-9.

[17] K. Jayaswal, D. K. Palwalia, and S. Kumar, "Performance investigation of PID controller in trajectory control of two-link robotic manipulator in medical robots," Journal of Interdisciplinary Mathematics, 2021. doi:10.1080/09720502.2021.1893444.

[18] K. Jayaswal and D. K. Palwalia, "Performance analysis of non-isolated DC-DC buck converter using resonant approach," Engineering, Technology \& Applied Science Research, vol. 8, no. 5, pp. 3350-3354, 2018, doi: 10.48084/etasr.2242.

[19] G. Kapoor, N. Gautam, K. jayaswal and S. Tripathi, "Protection of series capacitor compensated double circuit transmission line using wavelet transform," 2019 IEEE 5th International Conference for Convergence in Technology (I2CT), 2019, pp. 1-8, doi: 10.1109/I2CT45611.2019.9033583. 
[20] K. jayaswal, D. K. Palwalia, G. Jain, and P. Kumar, "Design-oriented analysis of non-isolated DC-DC buck converter", Ciencia e Tecnica Vitivinicola journal, vol. 30, no. 2, pp. 177-213, 2015.

[21] G. Kapoor, S. Tripathi, G. Jain and K. Jayaswal, "Detection of fault and identification of faulty phase in series capacitor compensated transmission line using wavelet transform," 2019 IEEE 5th International Conference for Convergence in Technology (I2CT), 2019, pp. 1-8, doi: 10.1109/I2CT45611.2019.9033807.

[22] K. Meena, K. Jayaswal and D. K. Palwalia, "Analysis of dual active bridge converter for solid state transformer application using single-phase shift control technique," 2020 International Conference on Inventive Computation Technologies (ICICT), 2020, pp. 1-6, doi: 10.1109/ICICT48043.2020.9112398.

[23] E. Rashedi, H. Nezamabadi-pour, and S. Saryazdi, "GSA: A gravitational search algorithm," Information sciences, vol. 179, no. 13, pp. 2232-2248, 2009, doi: 10.1016/j.ins.2009.03.004.

[24] M.M. Saidu, S. P. Jaiswal, K. Jayaswal, S. Mitra and V. S. Bhadoria, "A survey on: Automation of micro grid and micro distributed generation," Materials Today: Proceedings, 2020, doi: 10.1016/j.matpr.2020.11.404.

[25] M. Elsisi, M. Soliman, M. A. S. Aboelela, and W. Mansour, "GSA-based design of dual proportional integral load frequency controllers for nonlinear hydrothermal power system," International Scholarly and Scientific Research \& Innovation, vol. 9, no. 8, pp. 928-934, 2015.

[26] M. Sivakumar, P. Kannan, and S. C. Pandian, "Mitigation of PQ issues using an enhanced UPQC-based ANN approach," Journal of Circuits, Systems and Computers, vol. 28, no. 3, 2019, doi: 10.1142/S0218126619500464.

[27] N. Bianchi and M. Dai Pre, "Active power filter control using neural network technologies," IEE ProceedingsElectric Power Applications, vol. 150, no. 2, pp. 139-145, 2003, doi: 10.1049/ip-epa:20030009.

[28] R. K. Kumawat and D. K. Palwalia, "Half bridge module asymmetric multilevel inverter based on novel PWM control strategy," 2017 6th International Conference on Computer Applications In Electrical Engineering-Recent Advances (CERA), 2017, pp. 303-307, doi: 10.1109/CERA.2017.8343345.

[29] A. L. Jabar and T. A. Rashid, "A modified particle swarm optimization with neural network via eucliden distance," International journal of Recent Contributions from Engineering, Science \& IT (iJES), vol. 6, no. 1, pp.4-18, 2018, doi: 10.3991/ijes.v6i1.8080.

\section{BIOGRAPHIES OF AUTHORS}

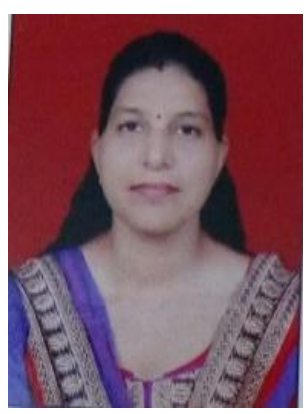

Ms. Annu Govind has done her M.Tech. in Power System and B.E. in Electrical Engineering from Malviya National Institute of Technology (MNIT), Jaipur. She is presently working as Associate Professor in IMS Engineering College Ghaziabad and pursuing Ph.D. in Electrical \& Electronics Engineering Department of Amity University Uttar Pradesh, Noida.

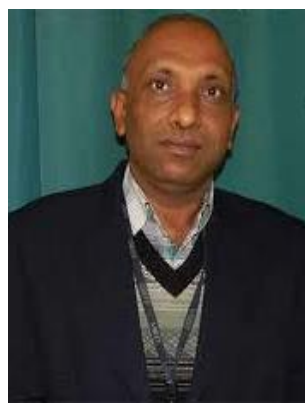

Dr. Vijay Kumar Tayal currently working Associate Professor in Electrical \& Electronics Engineering Department of Amity University, Uttar Pradesh, Noida. He has done B.E. with Honours in Electrical Engineering from Madan Mohan Malaviya Engineering College (MMMEC) Gorakhpur and M. Tech \& Ph. D. from National Institute of Technology, Kurushetra.

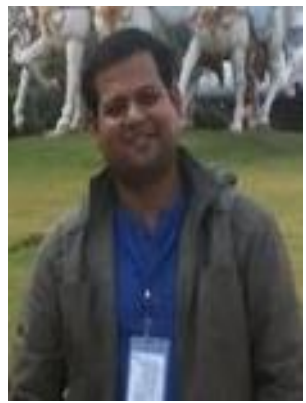

Dr. Prakash Kumar currently working as Assistant Professor in Electrical Engineering Department of Amity University, Patna. He has done his M. Tech \& Ph. D from Rajasthan Technical University (RTU), Kota. 